\title{
On the hot-zone design of Czochralski silicon growth for photovoltaic applications
}

\author{
L.Y. Huang ${ }^{\mathrm{a}}$, P.C. Lee ${ }^{\mathrm{a}}$, C.K. Hsieh ${ }^{\mathrm{b}}$, W.C. Hsu ${ }^{\mathrm{b}}$, C.W. Lan ${ }^{\mathrm{a}, *}$ \\ a Department of Chemical Engineering, National Taiwan University, Taipei 10617, Taiwan, ROC \\ ${ }^{\mathrm{b}}$ Sino-American Silicon (SAS) Products Inc., Science-Based Industrial Park, Hsinchu, Taiwan, ROC
}

Received 10 June 2003; accepted 5 September 2003

Communicated by D.T.J. Hurle

\begin{abstract}
Several hot-zone designs are presented for Czochralski photovoltaic silicon growth. Without sacrificing the crystal quality, a significant reduction of power and argon consumption was achieved, while the pulling rate was significantly increased. More importantly, the oxygen content in the grown crystals was greatly reduced leading to longer minority lifetime. The degradation rate of the graphite elements was greatly reduced as well. The design reported here included the radiation shield (molybdenum and graphite with different coatings), additional side and bottom insulations (graphite and graphite felt), and a top side insulation. Good agreement was found between computer modeling and experimental measurements in the power consumption and a reference temperature near the heater. Furthermore, the effect of the hot-zone design on the interface concavity is discussed through computer simulation.
\end{abstract}

(C) 2003 Elsevier B.V. All rights reserved.

PACS: $81.10-\mathrm{h} ; 61.82 \mathrm{Fk} ; 44.25 .+\mathrm{f} ;$ 47.27.Te; 81.10.Fq; 02.60.c6; 02.70Fj

Keywords: A1. Computer simulation; A1. Defects; A1. Heat transfer; A1. Interfaces; A1. Radiation; A2. Czochralski method; B2. Semiconducting silicon

\section{Introduction}

Most hot-zone designs have been focused on the improvement in ingot quality for the Czochralski silicon growth [1-5]. However, for photovoltaic applications, the cost of ingot pulling is one of the major concerns. More than $50 \%$ of the cost for a photovoltaic module is attributed to the ingot and wafer production [6]. Therefore, an efficient hot

\footnotetext{
*Corresponding author. Fax: + 886-223633917.
}

E-mail address: cwlan@ntu.edu.tw (C.W. Lan). zone for crystal growth is crucial for the cost reduction. With a better hot-zone design, the usage of the consumables, such as argon and graphite components, could be significantly reduced as well. Recently, a successful power-reduction project, as a joint effort of Siemens Solar Industries (SSI) and Northwest Energy Efficiency Alliance (NEEA), has shown that significant power reduction up to $40 \%$ can be achieved [7]. In addition, due to the redirected argon flow by the radiation shield, the actual argon usage, which is used to carry away silicon monoxide, can be reduced significantly. 
Such an improvement has shed light to a significant cost reduction for solar-cell modules using silicon single crystals and could have a great impact on the solar-energy applications for the near future.

In the SSI/NEEA project, FIDAP, a commercial CFD code, was used for model prediction [89] and the predicted power consumptions agreed reasonably well with the measured ones. However, the detailed contribution of each design element on the power saving was not investigated. Furthermore, the interface concavity was not considered, so that the potential influence of the hot-zone design on the crystal quality cannot be judged a priori. More importantly, since the pulling rate is directly related to the production yield, the maximum pulling rate without causing a too large interface concavity should also be an important factor to be considered as well. Recently, the effect of a molybdenum radiation shield on power reduction was reported by Sinno et al. [10] based on the simulation using FEMAG. About $10 \%$ of the power was saved for the growth of 4 in silicon in a Leybold EKZ 1300 puller. The calculated axial temperature distribution in the ingot was in good agreement with experiments. Reasonable agreement between the calculated interface shapes and observed ones for two different growth rates was also obtained by Dornberger and Ammon for a 6 in growth [11]. Beside the successful examples using FEMAG, STHAMAS [12], a software package developed by Müller's group in Germany, has emerged as a powerful tool for crystal growth modeling. A benchmark comparison with FEMAG and the code developed by Brown's group at MIT [13] on the Czochralski modeling has been reported showing a good agreement [14]. This gives us a great confidence in the hot-zone design using these modeling tools.

In this report, recent progress of our hot-zone designs for photovoltaic silicon growth is reported. Due to the high cost and risk of growth experiments, extensive design configurations were explored by using STHAMAS first, where the effects of each hot-zone component on the power consumption, interface concavity, and the crucible temperature could be investigated separately. Then, the growth experiments with the new hot- zone implementation were carried out. The power reduction by different components and materials, which are closely related to the cost, is compared and discussed. Furthermore, the final benefits from the design, such as the reduction in the power and argon consumption, lower oxygen content, longer minority lifetime, and the longer lifetime of graphite components, are demonstrated. In the next section, the computer modeling and experimental setup are briefly introduced, followed by the results and discussion. The conclusion and comments are given in Section 4.

\section{Computer simulation and growth experiments}

The study was focused on the 5.5-in silicon pulling (boron or phosphorous doping) using Kayex CG6000 pullers; both 14 and 16 in quartz crucibles were used, but only 16 in results are

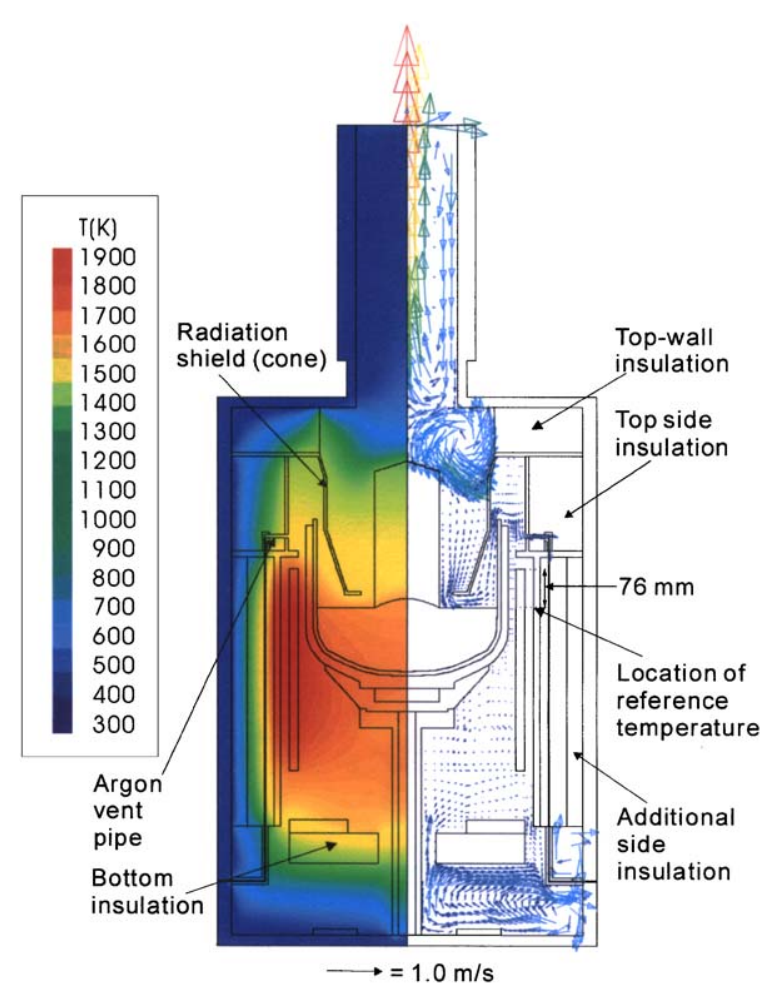

Fig. 1. Schematic of the hot zone for a CG6000 puller using 16 in crucible; typical thermal (left) and argon flow fields (right) are shown. 
presented here. A typical hot-zone configuration is shown in Fig. 1, where a typical thermal (left) and argon flow (right) fields are illustrated. The hotzone designs were focused on six major components: (1) radiation shield (or cone); (2) top side insulation; (3) additional side insulation; (4) bottom insulation; (5) top-wall insulation; and (6) argon venting. The cone material was either molybdenum (Plansee Inc.) or graphite (with $\mathrm{SiC}$ or Pyrolitic Carbon (PC) coating (NCK Inc.). The graphite felt (NCK Inc.) was used for all insulations, except the bottom insulation, where graphite was also used for comparison. Fig. 2 shows the photographs of some major hot-zone components. Although the molybdenum cone is believed to have a better performance due to its higher reflectivity, its cost is three times higher than that of the graphite ones. Therefore, the performance/ cost factor would be the major concern in practice. Similarly, graphite felt is also much more expensive than graphite. Both cone materials have limited lifetime due to surface degradation after $\mathrm{SiO}$ deposition and the followed reactions, as well as the weakened structure. Nevertheless, both cones have been used for more than 6 months and no significant difference on the performance was found.

The simulation tool STHAMAS was used for the modeling. It is a finite-volume-based simulation package developed by Müller's group in

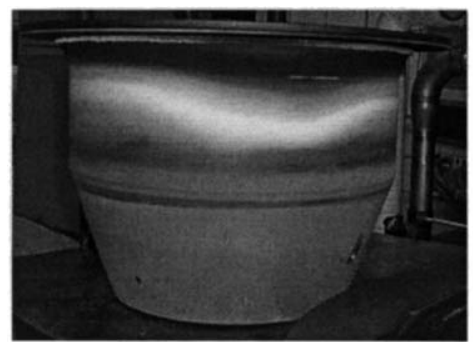

(a)

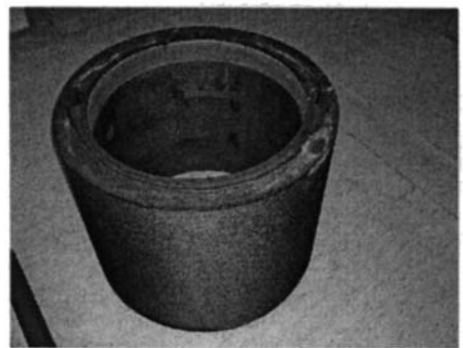

(c)

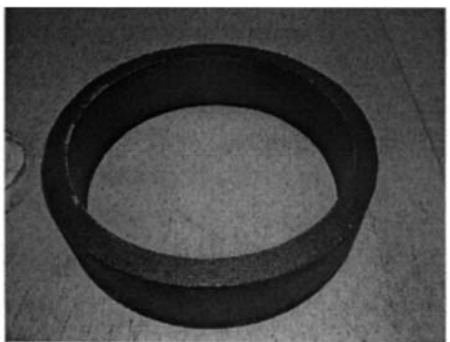

(b)

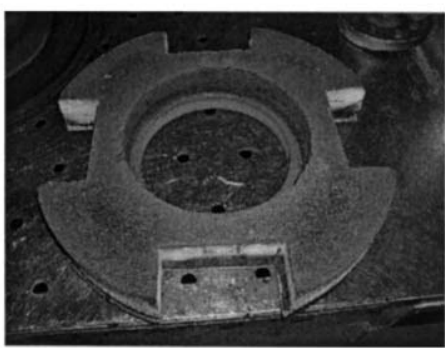

(d)

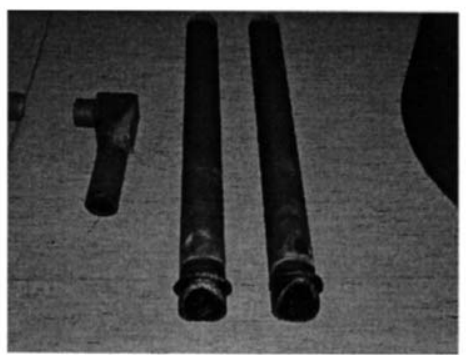

(e)

Fig. 2. Photographs of some important design components used in the growth experiments: (a) molybdenum cone; (b) cone support and top side insulation; (c) additional side insulation; (d) bottom insulation; and (e) the argon venting pipes (graphite). 
Germany. Before simulation, the system was divided into many blocks for the generation of the structured mesh within each block; incoherent meshes are allowed for different blocks. For some non-axisymmetric components, such as the argon venting pipe and the bottom insulation, a volume or surface average was considered along the angular direction. After grid generation, the radiation view factors were calculated before running heat flow simulation; the radiation was assumed to be gray and diffusive. At the beginning of the simulation, the interface was fixed for finding a suitable power usage having the melting temperature at the crystal/melt/gas tri-junction. Then, the interface update was turned on and the power was adjusted to satisfy the interface energy balance having the melting temperature at the trijunction. Argon flow calculation was also considered, but not the melt convection, where an effective melt thermal conductivity was adopted $[10,11,14]$. The total cell number used for the calculations was about 60,000-70,000. Each calculation took about $3 \mathrm{~h}$ of CPU time in a personal computer (P4-2GHz). In order to fit the experimental data, the thermal conductivity of the graphite support was adjusted slightly. It should be pointed out that there are some gaps between the graphite support and the felt, and an accurate description of the contact resistance is not possible. Therefore, instead of adjusting the felt properties, the thermal conductivity of the graphite support is chosen to fit the experimental data. After the value was set, it was used for the rest of calculations. Some physical properties used for simulation are listed in Table 1 for reference.

The growth experiments were carried out at SAS using Kayex CG6000 pullers. After melting down, the system was waiting for stabilization having a suitable power for seeding; this power value was usually the lowest for the growth. The power usage for the heater was recorded from the meter on the control panel, and double checked by a separated meter measuring the input current and voltage. In addition, a reference temperature near the heater, as shown in Fig. 1, was measured, and this temperature could also be used for process control. After successful seeding, the crystal was pulled automatically with diameter control using the image of the optical ring near the tri-junction line from a CCD camera. In order to ensure crystal quality, the growth rate was gradually decreased and controlled.

The actual growth speed varied along the body length and was recorded for comparison with the simulation. The interface concavity, only in very few cases, was measured by suddenly detaching the crystal from the melt. The grown ingot was cut and polished for sample measurements. The major properties measured included the resistivity mapping (using the four-point probe), oxygen content (using FTIR) and the lifetime mapping (using the microwave photoconductivity decay ( $\mu$-PCD) method). For N-type ingots, the oxygen precipitates can trap the minority carriers at the oxide interface [15], so that the lifetime decreases with the oxygen content quite sensitively. However, for

Table 1

Physical properties used in simulations [13]

\begin{tabular}{lcll}
\hline & Specific heat capacity $(\mathrm{J} / \mathrm{kg} \mathrm{K})$ & Thermal conductivity $(\mathrm{W} / \mathrm{mK})$ & Emissivity \\
\hline Silicon (solid) & 1084 & $96017 T^{-1.149}$ & 0.7 \\
Silicon (melt) & 915 & $110^{\mathrm{a}}$ & 0.3 \\
Graphite & 500 & $139.16 \exp \left(-7.84 \times 10^{-4} T\right)$ & 0.82 \\
Graphite felt (provided by NCK Inc.) & 1000 & $0.1773 \exp \left[0.7 \times 10^{-3}(T-273)\right]$ & 0.9 \\
Mo & 310 & 105.0 & 0.4 \\
SiC-coated graphite & 500 & $139.16 \exp \left(-7.84 \times 10^{-4} T\right)$ & 0.777 \\
PC-coated graphite & 500 & $139.16 \exp \left(-7.84 \times 10^{-4} T\right)$ & 0.4 \\
Steel & 500 & 15.0 & 0.45 \\
\hline
\end{tabular}

\footnotetext{
${ }^{\mathrm{a}}$ This is an effective thermal conductivity to take the convective effect into account.
} 
P-type ingots, the influence of oxygen on the lifetime was found less obvious. Therefore, the comparison for the minority lifetime was performed for phosphorous doping only.

\section{Results and discussion}

\subsection{Power consumption}

The original power and growth history is shown in Fig. 3 first. The power consumption ranged from 98 to $112 \mathrm{~kW}$. The initial pulling rate after seeding was very high up to $120 \mathrm{~mm} / \mathrm{h}$ for a better diameter control. At this stage, due to the large cooling from the crystal shoulder, a high speed for growth was inevitable. As the growth proceeded, the growth rate was reduced gradually to enhance growth stability. Near the end, the slower growth rate was used to increase the end-cone yield. Without this speed reduction, the risk was higher for a sudden detachment of the crystal from the melt causing large thermal-shock damage back to the bulk crystal. The average growth rate for body growth was about $45 \mathrm{~mm} / \mathrm{h}$. Based on the measured growth rate, we conducted thermal analysis using STHAMAS. The calculated power consumptions at different body length were in good

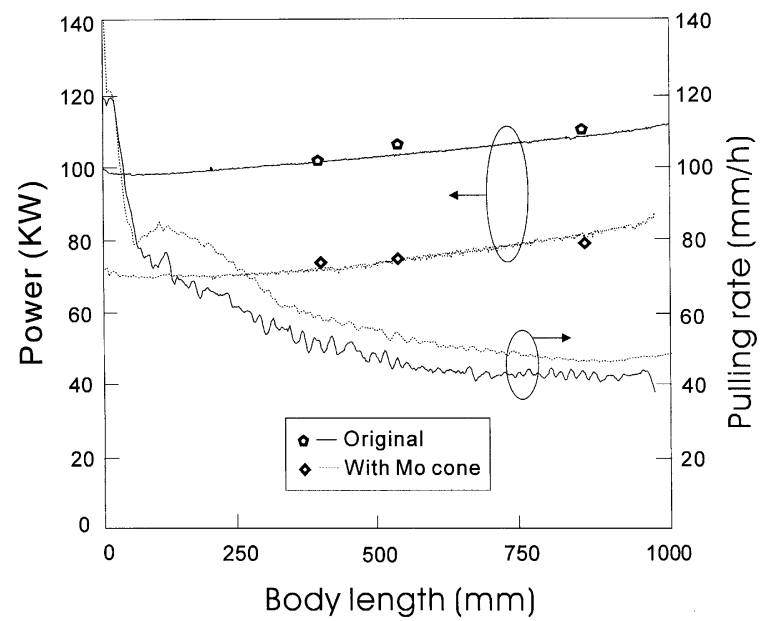

Fig. 3. History of power consumption and growth speed with and without molybdenum cone; the simulated data in power consumptions are included (diamond symbols) for comparison. agreement with the measured ones, as shown in Fig. 3; the effective thermal conductivity of the melt was used as listed in Table 1. The thermal field at the middle of the growth is shown in Fig. 4a. The interface concavity is about $9.9 \mathrm{~mm}$; other related values can be found in Table 2. A faster growth will lead to a significant increase in the interface concavity, which is harmful to the radial resistance variation (RRV) as well as the crystal quality. Fortunately, the specification for $\mathrm{RRV}$ in photovoltaic silicon wafer is quite loose. In general, the melt convection is quite strong in the silicon melt. If one assumes the dopant is completely mixed, the boron (segregation coefficient $K=0.8)$ or phosphorus $(K=0.35)$ concentration will be higher at the wafer center because the crystal forms earlier at the edge for a concave interface. This was also confirmed from the resistivity mapping of the wafers.

In order to reduce the power consumption and to increase the growth speed, a molybdenum cone was adopted first. The thickness of the cone was $3 \mathrm{~mm}$, while the shape is shown in Fig. $4 \mathrm{~b}$. To simplify the installation and to reduce the cost, the cone was fixed upon a graphite supporting ring; also see Fig. 2b. Outside the ring, an additional insulation using graphite felt, i.e., the top side insulation, was added. The power consumption and growth rate history during growth is shown in Fig. 3 as well. As shown, the power consumption was greatly reduced (ranging from 70 to $85 \mathrm{~kW}$ ) and the growth speed was significantly increased. The average growth rate in the body (more than $50 \mathrm{~mm} / \mathrm{h}$ ) was increased as well; the growth rate at the body length of $200 \mathrm{~mm}$ was up to $76 \mathrm{~mm} / \mathrm{h}$ and the crystal quality and RRV were still better than the original one. Again, near the end the growth rate was forced to slow down for the end-cone yield. The simulated power consumptions are labeled in Fig. 3. As shown, the agreement is quite satisfactory. Although the growth rate was slightly higher, the calculated interface concavity is much smaller (about $5.2 \mathrm{~mm}$ ) than the original design, as shown in Fig. 4b. The thermal distribution shown in Fig. 4b also indicates much lower heater and crucible temperatures. One can also get the values from Table 2 for details. In addition, as shown in Table 2, the calculated reference temperatures 

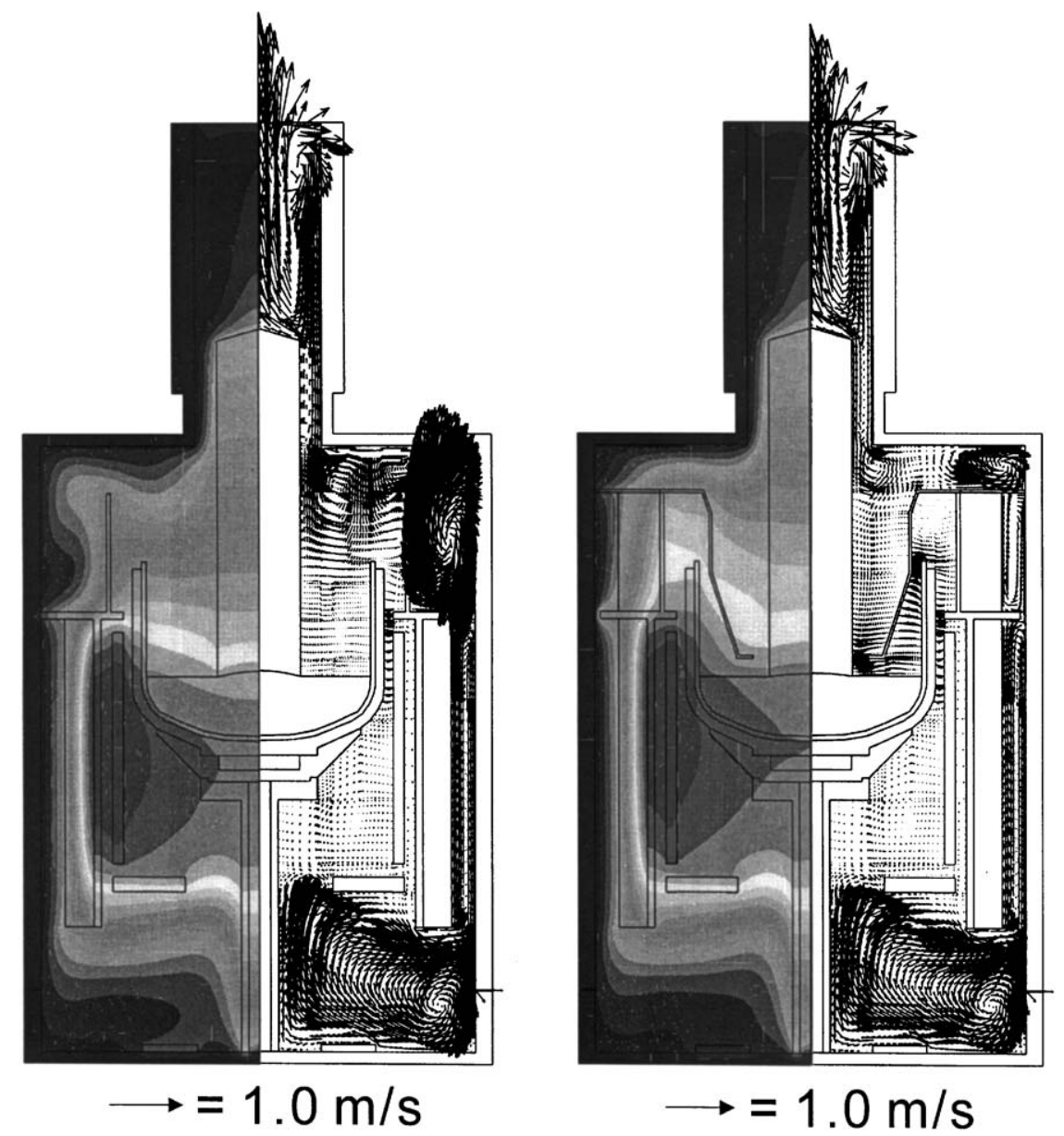

Fig. 4. Argon flow and thermal fields without (a); and with (b) the molybdenum cone.

were in reasonably good agreement with the measured ones.

Further improvement can be made for lower power consumption, higher growth rate, or lower interface concavity. However, these factors usually conflict to one another. Three additional insulations were considered. The simplest one, without much influence in the growth conditions, is to add additional side insulation. The cost for the graphite felt was quite high. However, the improvement in the power consumption was found not much, which contributed only about $2 \mathrm{~kW}$ on average. The bottom insulation was also considered, and two materials were tested. The results can be found in Table 2 as well. As shown, the graphite had little effect on the power consumption being about $2 \mathrm{~kW}$. On the contrary, the graphite felt had pretty good power saving. Additional $8 \mathrm{~kW}$ could be saved, and the maximum power consumption could be reduced to $64 \mathrm{~kW}$ with a SiC-coated graphite cone and additional side and graphite felt bottom insulations. In this case, the growth speed at the body growth was about $75 \mathrm{~mm} / \mathrm{h}$. Unfortunately, the interface concavity at such a speed was found to be the highest. Nevertheless, if we reduced the growth speed to $60 \mathrm{~mm} / \mathrm{h}$, the interface concavity was about the same as the original one $(9 \mathrm{~mm})$. In other words, the improvement is still quite satisfactory. It should be pointed out that the simulation for the bottom insulation is much more difficult due to its four-fold structure (Fig. 2c) and the empty space 
Table 2

Experimental and simulated results for different hot-zone designs

\begin{tabular}{|c|c|c|c|c|}
\hline & Original & Mo cone & $\begin{array}{l}\mathrm{C} / \mathrm{SiC} \text { cone }+ \text { graphite } \\
\text { bottom insulation }\end{array}$ & $\begin{array}{l}\mathrm{C} / \mathrm{SiC} \text { cone }+ \text { graphite } \\
\text { felt bottom insulation }\end{array}$ \\
\hline Power $(\mathrm{kW})^{\mathrm{a}}$ & 102.2 & 76.8 & 73.965 & 66.742 \\
\hline Pulling speed $(\mathrm{mm} / \mathrm{h})^{\mathrm{a}}$ & 45.3 & 51.1 & 64.3 & 75.7 \\
\hline Calculated power $(\mathrm{kW})$ & 102.4 & 74.3 & 71.5 & 64.5 \\
\hline [Each contribution] & & {$\left[17.4^{\mathrm{b}}+11^{\mathrm{c}}\right]$} & {$\left[14.2^{\mathrm{b}}+11^{\mathrm{c}}+2^{\mathrm{d}}\right]$} & {$\left[14.2^{\mathrm{b}}+11^{\mathrm{c}}+8^{\mathrm{d}}\right]$} \\
\hline $\begin{array}{l}\text { Energy per kilogram } \\
(\mathrm{kWh} / \mathrm{kg})^{\mathrm{a}}\end{array}$ & 63.333 & 45.484 & 38.724 & 25.944 \\
\hline Concavity $(\mathrm{mm})$ & 9.9 & 5.1 & 11.5 & 13.8 \\
\hline Highest temperature (K) & 2022.5 & 1915.9 & 1930.7 & 1915.1 \\
\hline $\begin{array}{l}\text { Highest crucible } \\
\text { temperature }(\mathrm{K})\end{array}$ & 1788.0 & 1744.5 & 1769.2 & 1765.5 \\
\hline $\begin{array}{l}\text { Referenced temperature } \\
(\mathrm{K})\end{array}$ & 1572.0 & 1525.0 & 1510.5 & 1496.1 \\
\hline [measured] $]^{\mathrm{a}}$ & {$[1585.0]$} & {$[1527.0]$} & [1511.0] & [1497.0] \\
\hline $\begin{array}{l}\text { Maximum von Mises } \\
\text { stress (10 MPa) }\end{array}$ & 2.11 & 1.71 & 1.62 & 1.90 \\
\hline
\end{tabular}

The additional side insulation contributed about $2 \mathrm{~kW}$.

${ }^{a}$ Experiment results.

${ }^{\mathrm{b}}$ Cone contribution.

${ }^{\mathrm{c}}$ Top-side insulation.

${ }^{\mathrm{d}}$ Bottom insulation.

left for the heater electrodes. These electrodes were made of conducting materials. If the insulation covered those connectors, significant overheating could cause electrode distortion. Therefore, some spacing was left over for the electrodes, and the area for the spacing was about one-third of the total area. Therefore, volume averaged thermal properties (graphite and graphite felt) were used for simulation.

Table 2 also summarizes the estimated contribution of each hot-zone component to the overall power consumption. As shown, the cone and the top insulation contributed the most being about $30 \mathrm{~kW}$. The side insulation was only $2-3 \mathrm{~kW}$. Additional $8 \mathrm{~kW}$ was reduced by the lower graphite felt insulation. Totally, up to $40 \mathrm{~kW}$ could be saved during growth. The relative power consumption per kilogram of crystal for different designs is also illustrated in Table 2. As shown, the maximum total saving $(\mathrm{kWh} / \mathrm{Kg})$ was more than $58 \%$, which is comparable to the SSI/NEEA design. Interestingly, if we allow a faster growth speed (about $75 \mathrm{~mm} / \mathrm{h}$ was feasible) toward the crystal end for the modified hot-zone designs, beside the lower power usage, the growth time could be reduced substantially. Then, additional $5 \%$ of power consumption could be saved, and the total power saving per $\mathrm{kg}$ ingot could be more than $60 \%$. Furthermore, the use of PC-coated graphite cone, which has a better reflectivity, gave a better performance than the SiC-coated one.

\subsection{Interface concavity and thermal stress}

Beside the power consumption, one important benefit from the hot-zone design is the smaller interface concavity at the same growth speed. As shown in Table 2 and Fig. 4, even with a higher growth speed, the interface concavity with the molybdenum cone was still smaller than the one without the cone, and this was confirmed by the direct observation of the detached interface shapes. According to simulation, it was also found that the cone shape and cone material were two major factors for the interface control. In general, the cone edge (or called the ring) needs to be close to the tri-junction as much as possible. If we reduce the inner diameter of the ring from $200 \mathrm{~mm}$ 
in Fig. $4 \mathrm{~b}$ to $170 \mathrm{~mm}$, the interface concavity can be reduced to $1.6 \mathrm{~mm}$ (from $5.1 \mathrm{~mm}$ in Fig. 4b). Unfortunately, $170 \mathrm{~mm}$ is too small to observe the optical ring for diameter control. Hence, $200 \mathrm{~mm}$ is a reasonable choice. On the other hand, with a smaller gap, say $20 \mathrm{~mm}(31 \mathrm{~mm}$ in Fig. 4b), between the cone and the melt surface, the interface concavity is also slightly reduced $(4.6 \mathrm{~mm})$. Again, lowering the cone position increases the risk of melt splashing. Replacing the cone material from molybdenum to SiC-coated graphite increases the interface concavity, as illustrated in Table 2. Fortunately, with PC coating, which has a higher reflectivity, the interface concavity can be reduced, but it is still not as good as molybdenum. Therefore, in view of the performance/cost ratio, the PC-coated graphite cone is believed to be a good choice in practice.

Beside the cone design, the top side insulation also contributed to the increase of the interface concavity. This is particularly obvious for the case with the top-wall insulation. Although additional several $\mathrm{kW}$ could be saved, the top-wall insulation was not used in practice. On the other hand, removing the top side-insulation was also helpful in reducing the interface concavity. However, as compared with its contribution on power saving, we still keep it in production. Furthermore, a severe interface concavity will lead to large RRV and larger von Mises thermal stress, which concentrates mainly near the tri-junction line. However, the higher axial gradients in the crystal due to the cone could also increase thermal stress. The calculated thermal stress can be found in Table 2. As shown, beside the case using the molybdenum cone, a smaller interface concavity still tends to have a smaller thermal stress. This is consistent with previous prediction [16], where the maximum stress is also located near the trijunction line. On the other hand, the contribution from the larger axial thermal gradients by the cone was found to be not too significant.

\subsection{Argon consumption and graphite degradation}

During silicon growth, the oxygen is dissolved from the crucible into the melt forming silicon monoxide ( $\mathrm{SiO}$ ). Carrying $\mathrm{SiO}$ away from the melt by argon flow is very important in practice. However, the overdeposition of $\mathrm{SiO}$ particles on a cooler surface, such as the chamber wall, the crucible inner wall, and the ingot surface could cause problems when the deposited particles fall down into the melt. With the cone installation, it was observed that the argon flow consumption could be significantly reduced without any obvious problems. The major reason was that the flow space between the cone and the melt was much smaller and the argon flow across the melt surface became faster. Accordingly, the removal of $\mathrm{SiO}$ became more effective. The argon flow rate could be reduced from 60 to $15 \mathrm{slpm}$ in this study. The argon flow path is shown by the vector field in Fig. 4. With the cone, near the melt surface no argon circulation is found, which is believed to be useful in minimizing the falling of the $\mathrm{SiO}$ particles from the upper cooler surface. On the other hand, as shown in Fig. 2a, the upper part of the cone still had significant $\mathrm{SiO}$ deposition. With the top-wall insulation, the deposition was reduced and its position higher due to the increase of the cone temperature, but completely removing the deposition was found difficult.

Beside the argon consumption, the original argon flow path was running through the graphite heater and $\mathrm{SiO}$ reacted with graphite forming silicon carbide. This deteriorated the heater and shortened heater's lifetime. By redirecting the argon to the side insulation through graphite pipes (as shown in Fig. 2e), it was found that the heater lifetime, as well as that of the graphite crucible, could be significantly elongated. Fig. 5 shows the effect of the Mo cone with the argon venting pipes on the degradation of the graphite crucible and the graphite heater. As shown, the degradation rates of both components were significantly reduced with the molybdenum cone. In Fig. 5a, the crucible thickness was defined as the radius of curvature at the corner. In Fig. 5b, the resistance increase was due to the heater thinning caused by hightemperature evaporation and the $\mathrm{SiC}$ formation. Beside the redirected argon flow, this lifetime enhancement is believed to be caused by the lower heater temperature due to the lower heating power. One can compare the heater and crucible temperatures for different hot zones in Table 2 to 


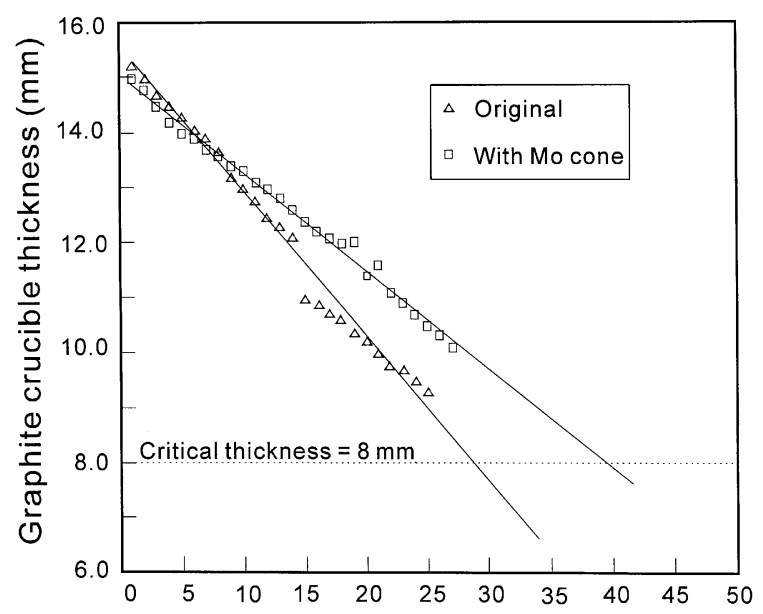

(a)

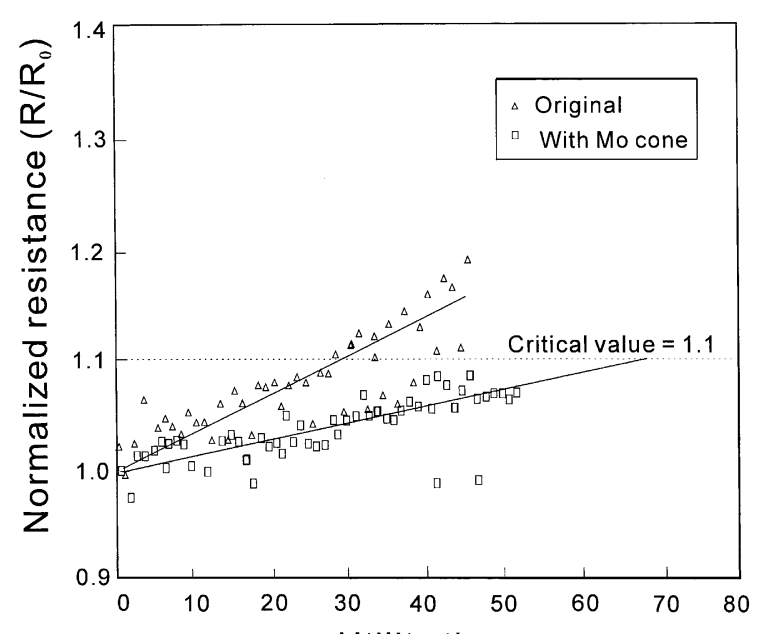

(b)

Utility times

Fig. 5. Effects of molybdenum cone with argon venting pipes on the degradation of graphite crucible (a); and graphite heater (b).

get a better idea. Furthermore, the position of the argon venting pipes was chosen to be as hot as possible, so that the pipes are not blocked by the overdeposition of $\mathrm{SiO}$ particles. In addition, with the cone, after growth the grown crystal surface was found very shining, without any obvious surface oxidation.

\subsection{Oxygen contents and minority lifetime}

Finally, beside cost reduction, the final goal of the hot-zone design is to produce better crystals for photovoltaic applications. One of the major indicators for the solar-cell performance is the lifetime of the minority carriers. Oxygen precipitates usually reduce the lifetime of minority carriers for the N-type silicon due to the formation of the interface traps at the oxide surfaces [15]. The oxygen content in the grown crystal is affected by many factors. However, the crucible temperature is believed to be an important one. With a lower crucible temperature, the oxygen dissolution into the melt could be less. Therefore, from the hotzone simulation, the crucible temperature in contact with the melt was calculated, and listed in Table 2. As shown, with a suitable hot zone, especially with the cone, the temperature was significantly lower. However, the crucible temperature was higher when the bottom insulation

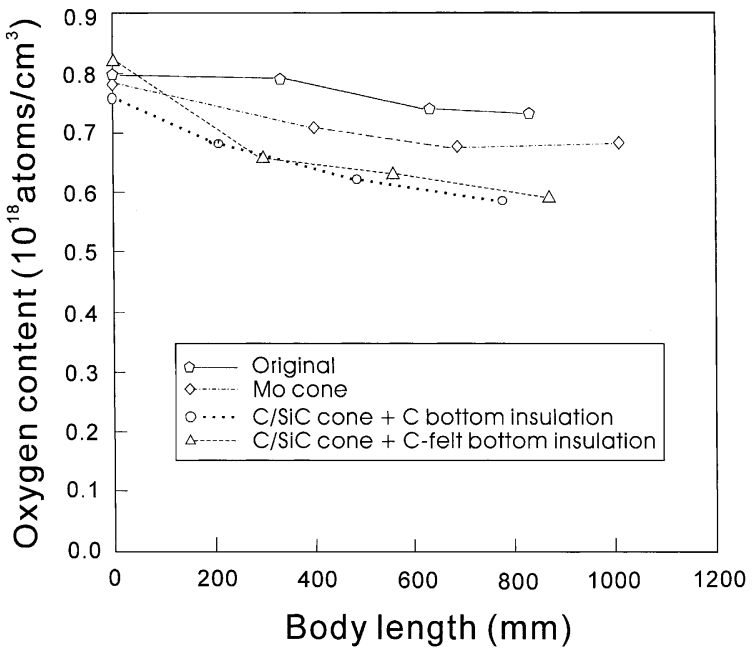

Fig. 6. Oxygen content at different growth distances for different hot-zone designs.

was added. Fig. 6 shows the distribution of oxygen content at different body length for different hot zones. As illustrated, with a cone, the oxygen content was greatly reduced. This information was found to be consistent with the calculated crucible temperature for the cases with and without the cone; the inconsistence among the cases having different cones and insulations was not clear. Because the pulling rates were not the same and 


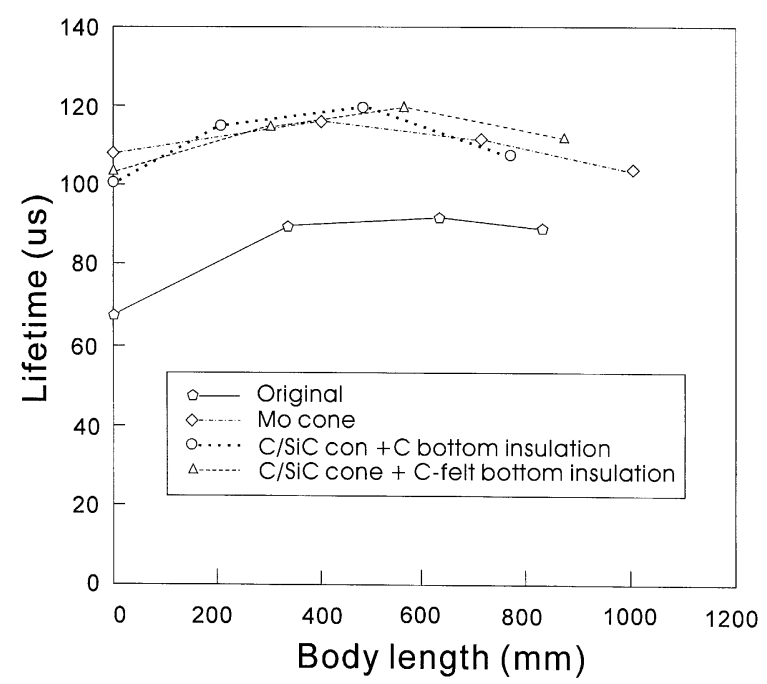

Fig. 7. Comparison of the minority lifetime at different growth distances for different hot-zone designs.

the amount of oxygen evaporation was not clear, further comparison is difficult. Nevertheless, the corresponding minority lifetimes were also illustrated in Fig. 7. As shown, most of them were consistent with the oxygen content in the wafers; however, in this case, the result for the molybdenum cone was not as good as expected. As just mentioned, the difference in the pulling rate could cause the discrepancy. Furthermore, the lower lifetime near the tail could be caused by the impurities left over near the end of the growth. In general, with a proper hot-zone design, the minority lifetime could be increased about $20 \%$.

\section{Conclusions and comments}

We have tested several hot-zone designs for 5.5 in silicon growth in Kayex CG6000 pullers. The simulation using STHAMAS was found reasonably consistent with experimental observations in the power consumption, argon usage, and oxygen content (based on the crucible temperature). The maximum power saving could be more than $50 \%$ depending on the design options. The growth speed could be substantially increased without sacrificing crystal quality. This was also confirmed by simulations based on the interface concavity and the maximum von Mises thermal stress. Additional insulations could reduce power consumption, but they could also increase the interface deformation, which is believed to be detrimental to the crystal quality. Therefore, for practical applications, care must be taken in the hot-zone design. On the other hand, due to the reduced crucible temperature, the oxygen content with the modified hot zones was lower than the original design leading to a longer minority lifetime. A significant reduction of argon consumption was found, while the lifetime for the graphite components could be elongated. The new designs have been routinely used in mass production of solar-grade silicon ingots at SAS, and the pay back is as anticipated. Therefore, the present successful example may inspire better hot-zone designs for further cost reduction and better ingot production for solar-cell industry.

\section{Acknowledgements}

This project was sponsored by the Ministry of Economics through the Strategic Technology Development Program. The software STHAMAS provided by Prof. G. Müller is highly appreciated. PCL also acknowledges the great hospitality of Prof. Müller's group during her software training and fruitful discussion. We are also grateful for the generous support from SAS, especially from the President Tom Yao and Vice President Doris Hsu.

\section{References}

[1] I. Yamashita, K. Shimizu, Y. Banba, Y. Shimanuki, A. Higuchi, H. Furuya, US Patent 4,981,549, January 1, 1991.

[2] K. Takano, I. Fusegewa, H. Yamagishi, US Patent 5,361,721, November 8, 1994.

[3] W. Zulehner, Mater. Sci. Eng. B 4 (1989) 1.

[4] T. Tsukada, M. Hozawa, J. Chem. Eng. Jpn. 23 (1991) 164.

[5] E. Dornberger, W.V. Ammon, J. Electrochem. Soc. 143 (1996) 1648.

[6] K.E. Knapp, T.L. Jester, Home Power, December 2000/ January 2001.

[7] B. Fickett, G. Mihalik, Semiconductor Fabtech., 1999, 10th Edition, Henley Publishing, London, p. 191. 
[8] P. Sabhapathy, M.E. Sacudean, J. Crystal Growth 97 (1989) 125.

[9] P. Sabhapathy, Report on computer simulation of flow and heat transfer in CG6000 during $144 \mathrm{~mm}$ diameter crystal growth with 16-in hot zone, July 1998.

[10] T. Sinno, E. Dornberger, W. von Ammon, R.A. Brown, F. Dupret, Mater. Sci. Eng. 28 (2000) 149.

[11] E. Dornberger, W. von Ammon, J. Electrochem. Soc. 143 (1996) 1648.

[12] J. Fainberg, Ph.D. Thesis, University of Erlangen, Nurnberg, 1999.
[13] R.A. Brown, T. Kinney, P. Sackinger, D. Bornside, J. Crystal Growth 97 (1989) 99.

[14] E. Dornberger, E. Tomzig, A. Seidl, S. Schmitt, H.-J. Leister, Ch. Schmitt, G. Müller, J. Crystal Growth 180 (1997) 461.

[15] J.M. Hwang, D.K. Schroder, J. Appl. Phys. 59 (1986) 2487.

[16] D. Bornside, T. Kinney, R.A. Brown, G. Kim, Int. J. Numer. Meth. Eng. 30 (1990) 133. 